\title{
JUIZADOS ESPECIAIS CRIMINAIS \\ Uma abordagem sociológica \\ sobre a informalização \\ da justiça penal no Brasil*
}

\author{
Rodrigo Ghiringhelli de Azevedo
}

\section{Introdução}

Os modernos Estados constitucionais podem ser visualizados como um conjunto de órgãos instituídos para a criação, aplicação e cumprimento das leis. Com a despersonalização do poder do Estado, este passa a fundar sua legitimidade não mais no carisma ou na tradição, mas em uma racionalidade legal, isto é, a crença na legalidade de ordenações regularmente estatuídas e nos direitos de mando dos chamados por essas ordenações a

* O presente artigo é um resumo do material empírico pesquisado e das conclusões da dissertação de mestrado, intitulada Informalização da justiça $e$ controle social: estudo sociológico da implantação dos Juizados Especiais Criminais em Porto Alegre, apresentada ao Programa de Pós-Graduação em Sociologia da UFRGS, em abril de 1999, tendo como orientador o prof. Dr. José Vicente Tavares dos Santos, e publicada pelo Instituto Brasileiro de Ciências Criminais. exercerem a autoridade (Weber, 1996, p. 172). Nesse tipo de Estado, a legitimidade deriva de as normas terem sido produzidas de modo formalmente válido, e da pretensão de que sejam respeitadas por todos aqueles situados no âmbito de poder desse Estado. ${ }^{1}$

Entre as principais características desse tipo de Estado está o controle centralizado dos meios de coerção. O Estado moderno apresenta-se, assim, como um complexo institucional artificialmente planejado e deliberadamente erigido, que tem como característica estrutural mais destacada o monopólio da violência legítima, garantido pelo que Weber chama de um quadro coativo (Weber, 1996, p. 28). O controle centralizado dos meios de coerção é fortalecido pela legitimidade que lhe confere a racionalidade jurídica, tornando a coerção mais tecnicamente sofisticada e exercida por um setor especializado do Estado. Esta característica constitui-se em um marco do que Elias denomina processo civilizador, com a adoção de for- 
mas mais racionais e previsíveis de instauração de processos e de punição pela prática de atos legal e previamente previstos como crimes. $^{2}$

Correspondendo, como paradigma teórico, aos modernos Estados liberais, a doutrina do direito como conjunto orgânico e universalmente válido de normas institucionalmente reconhecidas é progressivamente minada, na época contemporânea, por tentativas de adequar a regulamentação legal e a sua implementação pelas instâncias judiciais a um contexto de onde emergem discursos normativos rivais e se exige do Estado a execução de funções crescentemente político-administrativas.

A concentração de poder no Estado, a complexificação da sociedade e a regulamentação legal de setores cada vez mais amplos da vida social culmina, nas sociedades urbano-industriais do final do século XX, com a crise de legitimidade de uma ordem baseada em um discurso jurídico esvaziado, paralela e simultaneamente à crise fiscal do Estado-Providência. Começam a aparecer as fissuras neste aparato que ainda sustenta sua legitimidade em uma legalidade abstrata, constituída de acordo com normas gerais e apropriadamente promulgadas. Isso ocorre porque algumas premissas da racionalidade legal começam a ser minadas ou desgastadas (a divisão de poderes, a supremacia e generalidade da lei etc.) ante a concentração de expectativas no âmbito do poder executivo e dos recursos limitados de que dispõe para garantir a estabilidade social e a acumulação de capital.

Além disso, na medida em que se desgasta a crença na naturalidade das hierarquias de poder ou de distribuição de riqueza, a atividade governamental (inclusive a judicial) passa a depender cada vez mais de suas conseqüências em termos da satisfação de interesses fracionários. A linha divisória entre Estado e sociedade civil começa a se tornar mais difusa, ${ }^{3}$ aumentando a influência e a pressão sobre as políticas governamentais e as decisões judiciais por parte das forças sociais (desde as camadas subprivilegiadas até as grandes empresas multinacionais) que se rebelam contra a estrita observância de normas processuais e legais.

Busca-se, então, a renovação das fontes de legitimidade do Estado na sua capacidade em promover o desenvolvimento industrial e o cresci- mento econômico, vistos como padrão necessário e suficiente para o desempenho de cada Estado, e na garantia da efetividade dos mecanismos formais de controle social para a manutenção da ordem, justificando com isso deslocamentos na linha Estado/sociedade civil (Poggi, 1981, p. 140). A busca de prosperidade interna, como um fim em si mesmo, e a manutenção da ordem pública tornam-se as principais justificativas para a existência do Estado e a sua fonte de legitimidade, sobrepondo-se à mera racionalidade jurídico-legal.

No âmbito do sistema formal de controle social, ou seja, o sistema penal, as reformas institucionais que daí decorrem são apresentadas como tentativas de dar conta do aumento das taxas de criminalidade violenta, do crescimento geométrico da criminalidade organizada e do sentimento de insegurança que se verifica nos grandes aglomerados urbanos. A pressão da opinião pública, amplificada pelos meios de comunicação de massa, aponta no sentido de uma ampliação do âmbito de incidência do controle penal, tendo como paradigma preferencial a chamada política de "tolerância zero", adotada pela prefeitura de Nova York no início dos anos 90 e defendida por diferentes setores do espectro político. O pressuposto dessa política de segurança pública é a perda de eficácia das estratégias brandas ou informais de controle social. ${ }^{4}$

O problema é que as mudanças sociais ocorridas durante o século $\mathrm{XX}$ foram gradualmente enfraquecendo os mecanismos de controle comunitário sobre os comportamentos, exacerbando determinados focos de conflito antes abafados por hierarquias tradicionais de poder. Com o debilitamento dos controles sociais informais, o crescente sentimento social de desordem ampliou a demanda para que o Estado restaurasse a ordem mesmo em domínios familiares e de vizinhança. Para assegurar a consistência das expectativas normativas existentes na sociedade, o sistema penal passa a ter de responder a uma demanda crescente por resolução de conflitos privados.

Em sociedades com alto grau de complexidade, no entanto, se expressam muito mais expectativas normativas do que podem ser efetivamente institucionalizadas. Para assegurar a consis- 
tência das expectativas normativas criadas pelo direito, o mecanismo eleito é a pena ou sanção, principalmente pelo seu papel simbólico, e não por sua real incidência sobre os autores de delitos. Enquanto nas décadas de 60 e 70 a explosão de litigiosidade se deu sobretudo no domínio da justiça civil, no período mais recente (anos 80 e 90) a justiça penal assume o papel de protagonista, que além de dar conta da "velha" criminalidade individual, passa a ter de responder a uma nova demanda, já que desde a proteção ao meio ambiente até as regras de trânsito são ancoradas no poder de punir do Estado. Isto somado à crescente demanda social pelo fim da impunidade dos crimes de corrupção ("colarinho branco") e ao aumento da criminalidade urbana violenta coloca os tribunais no centro de um complexo problema de controle social.

Diante da crise fiscal do Estado e do aumento da demanda por controle penal, as novas estratégias de controle vão incorporar a contribuição dos estudos sociológicos e antropológicos que tiveram por objeto o sistema jurídico. Paralelamente aos mecanismos convencionais de administração da justiça, surgem novos mecanismos de resolução de conflitos através de instituições mais ágeis, relativa ou totalmente desprofissionalizadas e menos onerosas, de modo a maximizar o acesso aos serviços, diminuir a morosidade judicial e equacionar os conflitos por meio da mediação.

$\mathrm{Na}$ esfera penal, essas reformas operam mediante movimentos de despenalização e de informalização, na busca de alternativas de controle mais eficazes e menos dispendiosas do que as oferecidas pelo sistema penal tradicional. Quer se fundamentem em razões de legitimidade, quer privilegiem uma perspectiva de eficácia, as reformas, no sentido da informalização, assumem características diversas. No âmbito do direito material, pode ser adotada a forma direta de descriminalização, pela revogação da norma incriminatória, ou ser incorporados princípios gerais de aplicação da pena, excluindo de sua incidência os chamados delitos de bagatela. No âmbito do direito processual, as mudanças têm visado o alargamento do princípio de oportunidade da ação penal, conferindo ao acusado uma gama de alternativas (transação, sus- pensão condicional do processo) nos chamados delitos de menor potencial ofensivo, e incorporando a participação da vítima para o encaminhamento da questão. No âmbito processual, as alternativas de informalização apontam para a redução da competência do sistema penal tradicional em relação ao controle de condutas que permanecem sendo consideradas socialmente indesejáveis. São as chamadas soluções conciliatórias, que visam promover a interação face a face entre vítima $\mathrm{e}$ acusado como forma de superar o conflito que está na origem do delito. As soluções de conciliação constituem uma das manifestações mais expressivas do movimento de "deslegalização" ou "informalização" da justiça.

Nas heterogêneas comunidades urbanas contemporâneas, os programas de mediação e informalização da justiça penal obtêm uma rápida adesão graças à insatisfação com as sanções penais tradicionais para a solução de disputas e conflitos interpessoais, e apelam para as estruturas existentes na comunidade, embora muitas vezes não passem de um apêndice do sistema legal formal. De qualquer forma, correspondem à busca de alternativas de controle mais eficazes e menos onerosas do que as oferecidas pelo sistema penal tradicional, que permitam um tratamento individualizado, particularista, de cada caso concreto, em vez da orientação pela generalidade e universalidade das normas jurídicas.

Pesquisas sobre os modelos de informalização adotados em diversos Estados norte-americanos identificaram uma importante diferenciação, embora determinadas características fossem recorrentes. ${ }^{5}$ Em alguns casos, enfatiza-se a mediação como processo terapêutico e a pressão da comunidade é o meio para alcançar soluções voluntariamente acordadas entre as partes, no interior das cortes tradicionais. Em outros casos, os modelos apresentam-se como uma alternativa ao sistema formal, por exemplo, as chamadas community courts, que tem jurisdição exclusiva sobre certas ofensas. A corte comunitária tem funções conciliatórias e adjudicatórias, e os mediadores são eleitos pela comunidade onde residem e recebem um treinamento formal mínimo. Esse modelo aproxima-se da chamada democracia participativa, com o envol- 
vimento maior da comunidade em questões antes restritas e resolvidas pelo aparato estatal.

Em que pese a existência de modelos diferenciados, os elementos conceituais que configuram um tipo ideal de informalização da justiça nos Estados contemporâneos são: estrutura menos burocrática e relativamente mais próxima do meio social em que atua; aposta na capacidade dos disputantes de promover sua própria defesa, diminuindo a necessidade de profissionais e o uso da linguagem legal formal; preferência por normas substantivas e procedimentais mais flexíveis, particularistas, ad hoc; mediação e conciliação entre as partes mais do que a adjudicação de culpa; participação de não juristas como mediadores; preocupação com uma grande variedade de assuntos e evidências, rompendo com a máxima de que "o que não está no processo não está no mundo"; facilitação do acesso aos serviços judiciais para pessoas com recursos limitados para assegurar auxílio legal profissional; ambiente mais humano e cuidadoso, com uma justiça resolutiva rápida, e ênfase em uma maior imparcialidade, durabilidade e mútua concordância no resultado; geração de um senso de comunidade e estabelecimento de um controle local através da resolução judicial de conflitos; maior relevância em sanções não coercitivas para se obter acatamento.

\section{A Lei 9.0999/95 e a informalização da jus- tiça penal no Brasil}

No Brasil, a incorporação dessas inovações no sistema judicial teve impulso a partir dos anos 80, em especial após a promulgação da Constituição de 1988. Uma série de novos mecanismos para a solução de litígios foi criada com vistas à agilização dos trâmites processuais, entre os quais têm um significado relevante os Juizados Especiais Cíveis e Criminais, voltados para as chamadas pequenas causas e para os delitos de menor potencial ofensivo, previstos no ordenamento constitucional e regulamentados pela Lei Federal n. 9.099, de setembro de 1995 .

A implantação dos Juizados Especiais Criminais (JEC) integra uma lógica de informalização entendida não como a renúncia do Estado ao controle de condutas e no alargamento das margens de tolerância, mas como a procura de alternativas de controle mais eficazes e menos onerosas (Dias e Andrade, 1992, p. 403). Para esses Juizados vão confluir determinados tipos de delitos (com pena máxima em abstrato até um ano) e de acusados (não reincidentes). Com a sua implantação, espera-se que as antigas varas criminais possam atuar com maior prioridade sobre os crimes de maior potencial ofensivo.

Promulgada a Lei 9.099/95, o rito processual nela previsto passou a ser imediatamente aplicado, pelas Varas Criminais comuns, para os delitos de menor potencial ofensivo, especialmente a suspensão condicional do processo e as novas alternativas de conciliação entre vítima e autor do fato e de transação entre Ministério Público e autor do fato.

Porto Alegre foi uma das primeiras comarcas de grande porte a criar os Juizados Especiais Criminais, que passaram a ter competência exclusiva para o processamento dos delitos previstos na lei 9.099/95, com a edição da Lei Estadual n. 10.675, em 2 de janeiro de 1996, que criou o Sistema dos Juizados Especiais Cíveis e Criminais no Estado do Rio Grande do Sul.

Pelo pioneirismo de sua implantação, ${ }^{6}$ os Juizados Especiais Criminais de Porto Alegre constituem-se em um importante laboratório para a verificação da aplicabilidade dos dispositivos da Lei 9.099/95, das mudanças no movimento processual efetivamente ocorridas, assim como das dificuldades estruturais existentes na máquina burocrática do poder judiciário no sentido de oferecer uma prestação de justiça mais ágil e voltada para a defesa dos interesses e a resolução dos dilemas da clientela do sistema penal (vítimas e acusados).

A Lei 9.099/95 deu aos Juizados Especiais Criminais a competência para a conciliação e o julgamento das infrações penais de menor potencial ofensivo, que compreendem as contravenções penais (Decreto-Lei n. 3.688, de 03.10.1941) e os crimes cuja lei penal comine pena máxima não superior a um ano de detenção ou reclusão, excetuados os delitos para os quais está previsto um procedimento especial. 
Até a edição dessa Lei, as contravenções penais e os delitos punidos com pena de detenção eram processados pelo rito processual previsto no Capítulo V, Título II, do Livro II (art. 531 a 540) do Código de Processo Penal, denominado Processo Sumário. Pouca diferença havia entre este tipo de procedimento e o Processo Ordinário, aplicado aos delitos apenados com reclusão. A lei previa apenas a redução de alguns prazos e o abreviamento de determinados momentos processuais, mas a estrutura do processo era basicamente a mesma: inquérito policial, denúncia do Ministério Público, interrogatório do réu, defesa prévia, audiência de instrução, debates orais, julgamento. Não havia a possibilidade de reparação civil dos danos sofridos pela vítima no próprio processo penal, relegando-a ao papel de mero informante da justiça penal. Nem tinha o réu qualquer interesse em reconhecer o fato que lhe era imputado, com a negociação em torno da pena.

De acordo com o que estabelece a legislação no art. 62 da Lei 9.099/95, o processo perante os Juizados Especiais Criminais deve ser orientado pelos critérios de oralidade, informalidade, economia processual e celeridade, objetivando, sempre que possível, a reparação dos danos sofridos pela vítima e a aplicação de pena não privativa de liberdade. Dispensando a realização do inquérito policial, a Lei 9.099/95 determina que a autoridade policial, ao tomar conhecimento do fato delituoso, deve imediatamente lavrar um termo circunstanciado do ocorrido e encaminhá-lo ao Juizado, se possível com o autor do fato e a vítima, providenciando a requisição dos exames periciais necessários para a comprovação da materialidade do fato (art. 69).

Não sendo possível o comparecimento imediato de qualquer dos envolvidos ao Juizado, a Secretaria do Juizado deverá providenciar a intimação da vítima e do autor do fato, por correspondência com aviso de recebimento, para que compareçam à audiência preliminar (art. 71). Nesta, presentes o representante do Ministério Público, o autor do fato e a vítima, acompanhados de advogado, o juiz esclarecerá sobre a possibilidade de composição dos danos, assim como sobre as conseqüências da aceitação da proposta de apli- cação imediata de pena não privativa de liberdade ao autor do fato (art. 72).

Nos crimes de ação penal privada e de ação penal pública condicionada à representação, o acordo para a composição dos danos extingue a punibilidade. Não obtido o acordo, o juiz dá imediatamente à vítima a oportunidade de exercer o direito de oferecer queixa-crime ou representação verbal (art. 75). Havendo queixa-crime ou representação ou sendo o crime de ação penal pública incondicionada, o Ministério Público poderá propor ao autor do fato a transação penal, com a aplicação imediata de pena restritiva de direitos ou multa, a não ser no caso de o acusado ser reincidente ou de "não indicarem os antecedentes, a conduta social e a personalidade do agente, bem como os motivos e as circunstâncias, ser necessária e suficiente a adoção da medida" (art. 76). Não aceita a proposta, o representante do Ministério Público oferecerá ao juiz, de imediato, uma denúncia oral, e o processo seguirá o rito sumaríssimo, previsto na Lei. Oferecida a denúncia, poderá ainda o representante do Ministério Público propor a suspensão do processo por dois a quatro anos, desde que o denunciado não esteja sendo processado ou não tenha sido condenado por outro crime. A suspensão será revogada se, no curso do prazo, o denunciado for processado por outro crime ou descumprir qualquer outra condição imposta. Expirado o prazo sem revogação, o juiz declarará extinta a punibilidade.

Caso não seja possível a suspensão do processo, o juiz deverá intimar as partes para a audiência de instrução e julgamento, que se inicia com a resposta oral da defesa à acusação formulada na denúncia ou queixa-crime. Aceita a argumentação da defesa, o juiz não recebe a denúncia ou queixa e encerra o processo. Recebida a denúncia ou queixa, são ouvidas a vítima e as testemunhas de acusação e de defesa, o acusado é interrogado e realizam-se os debates orais entre a defesa e a acusação. Em seguida, o juiz profere a sentença final condenatória ou absolutória.

Os recursos previstos pela Lei $9.099 / 95-\mathrm{a}$ apelação (em caso de sentença condenatória ou absolutória ou da decisão de rejeição da denúncia ou queixa) e os embargos de declaração (em caso 
de obscuridade, contradição, omissão ou dúvida na sentença) - são encaminhados a uma Turma Recursal composta de três juízes em exercício no primeiro grau de jurisdição.

\section{A implantação dos Juizados Especiais Cri- minais em Porto Alegre}

Para dar conta da análise do período de implantação dos Juizados Especiais Criminais na Comarca de Porto Alegre, a partir de uma perspectiva sociológica, foi adotado o método do estudo de caso, reunindo dados a partir de diferentes técnicas de pesquisa, para abarcar o conjunto de questões que deveriam ser enfrentadas.

Como se sabe, as instâncias judiciais singularizam-se, entre as demais instâncias de controle social, por serem as mais opacas e resistentes à "devassa" da investigação sociológica. Tal situação é compreensível, uma vez que, de todas as instituições, são os tribunais judiciais aqueles cuja legitimidade depende em maior medida da integridade de uma imagem decantada e hipostasiada em séculos de teorização política e jurídica (Dias e Andrade, 1992, pp. 527-528).

A análise de um objeto com este grau de complexidade compreende uma série de passos fundamentais na investigação: a construção do objeto científico; a relação entre o investigador e o investigado; o questionamento dos métodos e técnicas de investigação; a perspectiva da descontinuidade do pensamento sociológico no momento da elaboração interpretativa. É a perspectiva da complexidade, "mediante a qual o conhecimento é definido como um processo multidimensional, marcado pela diversidade, pela multiplicidade e pela multidimensionalidade" (Tavares dos Santos, 1995, p. 74). O reconhecimento dos limites de toda técnica e da própria relação entre sujeito-investigador e sujeito-investigado leva a um pluralismo teórico-metodológico.

Em um primeiro momento, buscou-se obter os dados estatísticos disponíveis para o período pesquisado. Coletados e tabulados pela Corregedoria Geral de Justiça do Tribunal de Justiça do Rio Grande do Sul, com o auxílio da Procergs, os dados obtidos dizem respeito ao movimento processual penal na comarca de Porto Alegre, no período imediatamente anterior (1994 e 1995) e posterior (1996 e 1997) à implantação dos Juizados. Também estavam disponíveis as decisões terminativas adotadas nos Juizados Especiais Criminais de Porto Alegre, cuja fonte eram os mapas de movimento processual fornecidos mensalmente pelas secretarias dos Juizados à Corregedoria Geral de Justiça. Por fim, obteve-se também o gráfico comparativo de morosidade judicial entre os Juizados e as Varas Criminais, para os processos concluídos no primeiro semestre de 1998.

A partir do levantamento de dados estatísticos acima citados, e levando em consideração a carência de dados quanto a uma série de elementos essenciais para a compreensão de como a lei vem sendo aplicada na prática (tipos de delito, dados sobre as partes, tipos de conflito etc.), partiu-se para a etapa de observação sistemática de audiências nesses Juizados, nos meses de junho a outubro de 1998.

Quando da realização das observações, já havia entrado em vigor o novo Código Nacional de Trânsito, retirando dos Juizados Especiais Criminais a competência para julgar a maioria dos delitos de trânsito. Embora no primeiro semestre ainda estivessem em funcionamento os três Juizados especializados neste tipo de delito, extintos em agosto de 1998, optamos por restringir a observação aos JEC comuns, que passaram a julgar também os poucos delitos de trânsito que mantiveram a pena máxima até um ano (por exemplo, direção sem habilitação), para que a análise pudesse contemplar essa nova situação.

Ingressando nas salas de audiência como qualquer estagiário de direito, realizamos o trabalho de observação sistemática de um total de sessenta audiências, sendo 28 delas nos Fóruns Regionais e 32 no Fórum Central. A verificação do que efetivamente ocorre no momento de interação face a face entre os operadores jurídicos do sistema e a sua clientela permitiu verificar a existência de uma série de padrões de judicialização de conflitos nos Juizados Especiais Criminais. Foram constatados alguns tipos de delito predominantes, vinculados a determinadas formas de 
conflitualidade social. Em relação às partes envolvidas, foi possível verificar como se distribuem vítimas e autores do fato a partir da variável de gênero. Também foi possível identificar como tem sido alcançada a conciliação ou a transação penal, ou seja, qual o conteúdo concreto deste tipo de solução nos casos observados, bem como as diversas situações em que o juiz é colocado diante de limitações estruturais para o exato cumprimento de que dispõe a legislação (ausência de defensor para as partes, ausência do Ministério Público etc.).

Após a tabulação dos dados estatísticos e a observação das audiências nos Juizados de Porto Alegre, partimos para as entrevistas com juízes que atuavam ou haviam atuado nesses Juizados, já que a observação das audiências indicava que, entre os operadores jurídicos, cabia aos juízes um papel preponderante na dinâmica de funcionamento dos novos Juizados, conferindo maior ou menor eficácia dos instrumentos processuais previstos pela Lei 9.099/95. Foram entrevistados seis juízes criminais, contemplando a diversidade de experiências, fruto do maior ou menor tempo de atuação nos Juizados, bem como pela atuação em diferentes Fóruns Regionais. Entre os entrevistados, encontramos juízes que atuavam nos Juizados Criminais desde sua implantação, em 1996, e outros que estavam substituindo o titular havia apenas um mês. Também encontramos profissionais que já haviam atuado em outros Juizados, como os de trânsito, e agora tinham sido realocados para um Juizado comum, além de juízes que vinham de experiências em Juizados Especiais no interior do Estado. Quanto à diversidade territorial, as entrevistas contemplaram juízes com passagem por dois Juizados do Fórum Central, pelos Juizados Regionais de Sarandi, Alto Petrópolis e Partenon.

Com a implantação dos Juizados Especiais, havia a expectativa de uma significativa redução do movimento processual nas Varas Criminais Comuns, que poderiam, assim, concentrar a atenção nos delitos mais graves. A análise do movimento processual verificado na Comarca de Porto Alegre nos dois anos anteriores e posteriores à implantação não confirma essa expectativa.
Tomando por base os dados fornecidos pelos mapas de andamento processual da Corregedoria Geral de Justiça do Tribunal de Justiça do Rio Grande do Sul referentes à Comarca de Porto Alegre para o período considerado, o que se verifica é que, enquanto nos anos de 1994 e 1995 foram distribuídos para as Varas Criminais Comuns em torno de 6.000 processos por ano, em 1996 o número de processos distribuídos salta para 54.687, baixando para 37.608 processos no ano de 1997.

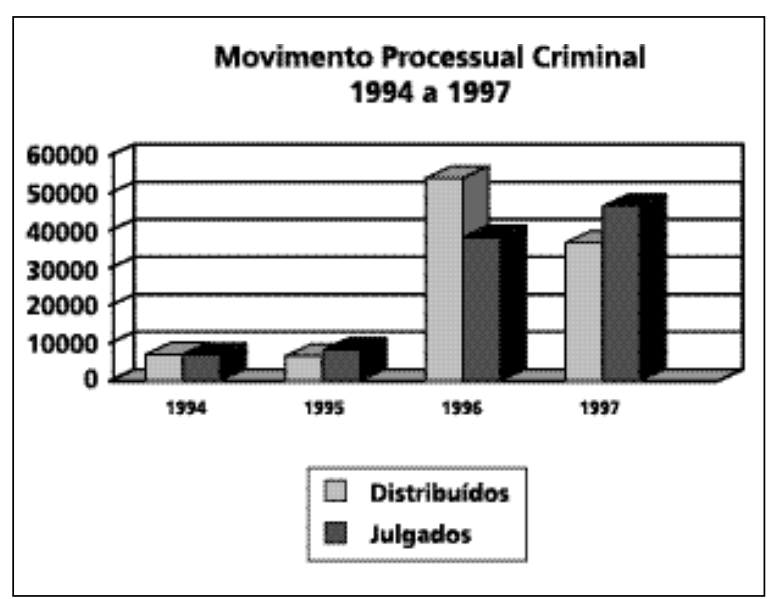

Apesar da significativa redução percentual, o volume de processos distribuídos nas antigas Varas Criminais se mantém praticamente inalterado. Como essas Varas foram reduzidas de 18 para 14 a partir da criação dos Juizados, há de fato um aumento do número de processos para as Varas Criminais Comuns. A conclusão é que, em vez de assumir uma parcela dos processos criminais das Varas Comuns, os Juizados Especiais Criminais passaram a dar conta de um tipo de delituosidade que não chegava até as Varas Judiciais, sendo resolvido através de processos informais de "mediação" nas Delegacias de Polícia ou pelo puro e simples "engavetamento". Com a entrada em vigor da Lei 9.099/95, as ocorrências policiais deste tipo de crime, que se encontravam nas Delegacias, aguardando a realização de inquérito policial, e que normalmente resultavam em arquivamento pela própria Polícia Civil, foram remetidas para os Juizados Especiais.

Quanto ao tempo médio de tramitação dos processos criminais, constata-se que o rito processual adotado pelos Juizados Especiais é efetiva- 
mente mais rápido do que nas Varas Criminais. Os dados disponíveis quanto à morosidade judicial dizem respeito ao tempo médio de tramitação dos processos criminais encerrados no primeiro semestre do ano de 1998 em Porto Alegre. Enquanto nas Varas Criminais o tempo médio de tramitação foi de 520 dias, nos Juizados Especiais Criminais a média foi de 130 dias de tramitação.

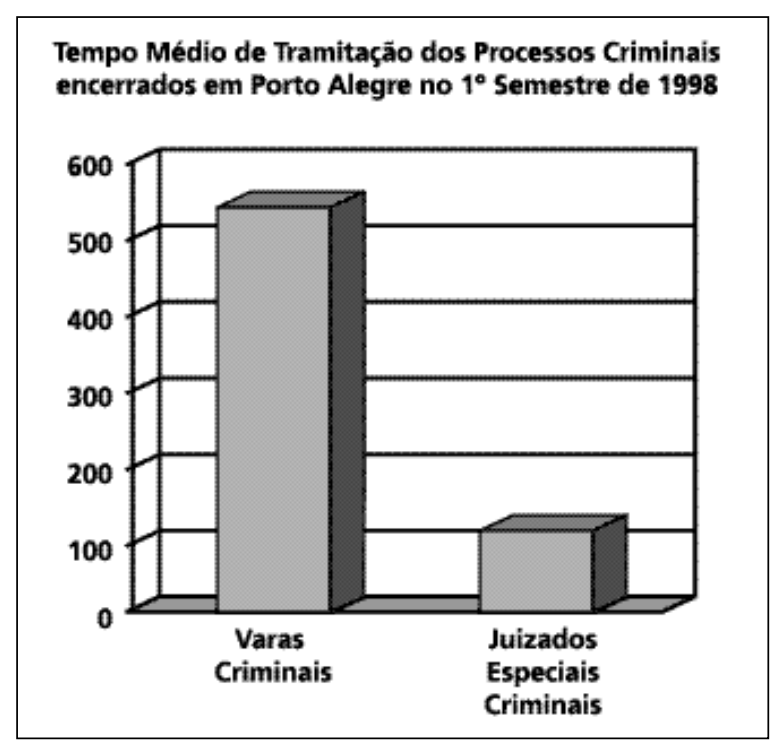

Uma das principais evidências obtidas a partir da análise dos mapas de andamento processual da Corregedoria Geral de Justiça é quanto ao alto número de processos cujo término se deveu ao arquivamento, situação em que não chega a ser realizada nenhuma audiência durante o processo.

Como se pode verificar pelas entrevistas realizadas e em contato com os próprios funcionários dos cartórios, isto ocorreu em grande parte porque um dos dispositivos da Lei 9.099/95 não foi respeitado pelas Delegacias de Polícia, muito menos pelas secretarias de muitos dos Juizados Especiais, nesse período de implantação: a intimação das partes para a audiência de conciliação (art. 71 da Lei 9.099/95).

Indo até a Delegacia para registrar a ocorrência, a vítima permanecia aguardando o encaminhamento judicial da questão. Não sendo intimada para a audiência de conciliação, e nem avisada de que o registro na polícia não era considerado uma representação, passados seis meses o processo era arquivado por decadência do direito de representação (art. 103 do Código Penal), resultando em uma situação de impunidade e na manutenção da descrença da população quanto à possibilidade de judicialização desse tipo de delito. Outra causa comum de arquivamento é o não encaminhamento, pela Polícia Judiciária, dos exames de corpo de delito, necessários para a comprovação da materialidade do fato.

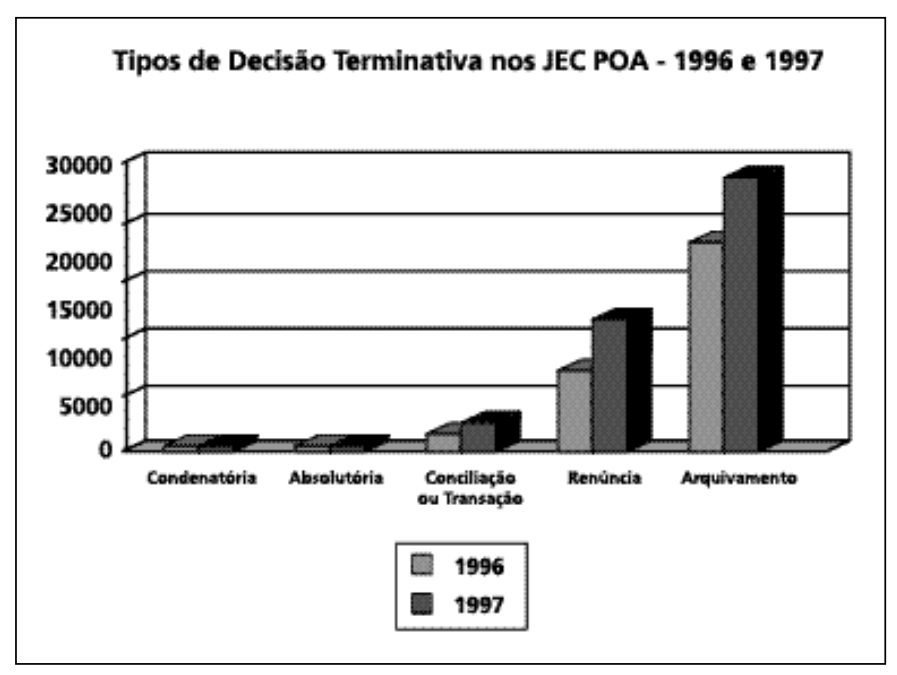

Entre os mais de cem delitos considerados pela Lei 9.099/95 de menor potencial ofensivo, por terem pena de prisão até um ano, tanto a observação das audiências quanto as entrevistas com os juízes que atuam nos Juizados Especiais Criminais de Porto Alegre confirmaram uma ampla predominância de dois tipos penais: os delitos de ameaça e de lesões corporais leves, que juntos corresponderam a $76 \%$ das audiências observadas.

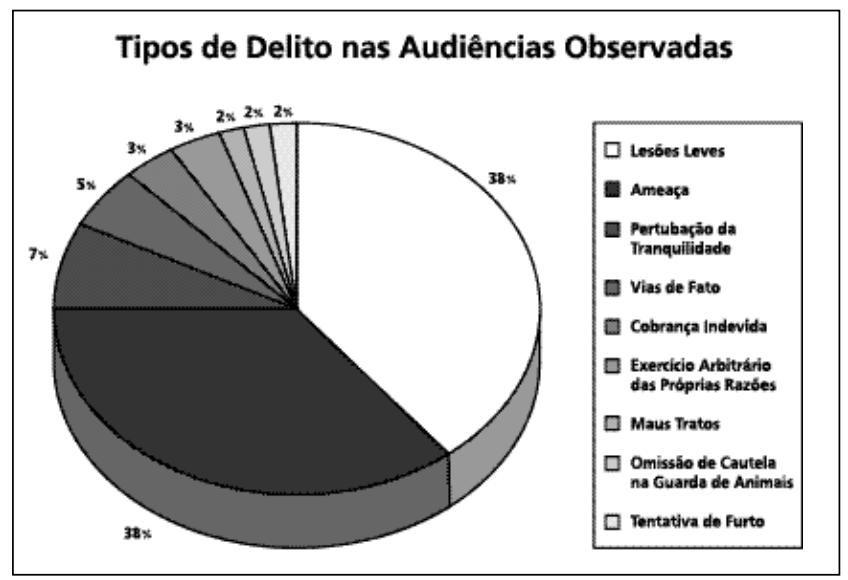


A observação das audiências permitiu também verificar quais os conflitos sociais que estão por trás dos delitos tipificados pela lei penal. Nesse sentido, constatou-se que a maioria dos delitos de menor potencial ofensivo é originária de situações de conflito entre vizinhos (41\%), entre cônjuges $(17 \%)$, entre parentes (10\%), ou em relacionamentos entre consumidor e comerciante (10\%). Além destes, foram também encontrados conflitos na relação entre patrão e empregado (8\%), brigas eventuais em locais públicos entre desconhecidos (5\%), e ainda alguns conflitos de trânsito (5\%), embora a grande maioria dos delitos de trânsito tenha retornado às Varas Criminais, com a elevação das penas previstas pelo novo Código Nacional de Trânsito.

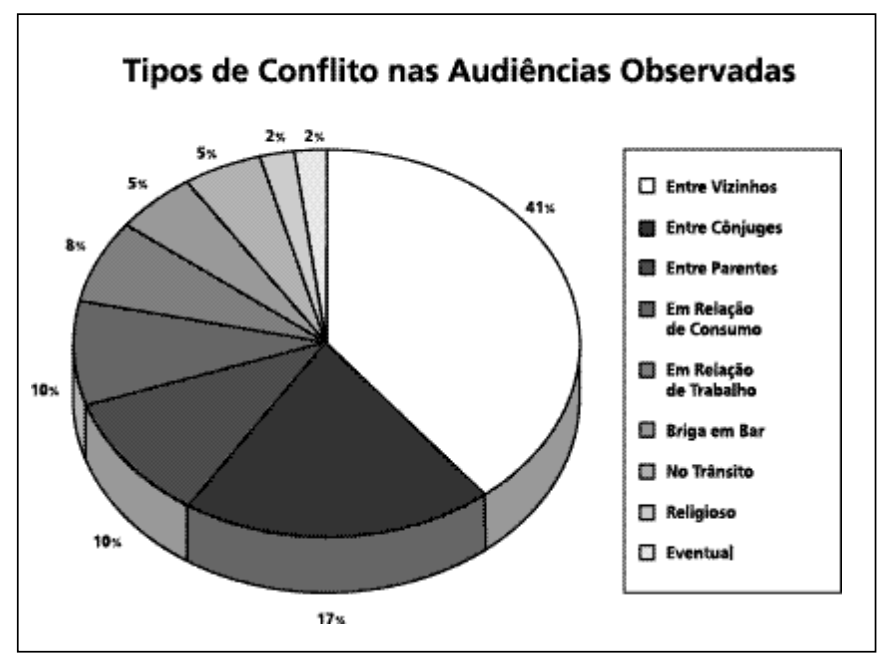

Deparando-se com um tipo de conflitualidade social que poucas vezes chegava até a sala de audiências, e tendo de conduzir um processo de conciliação entre os envolvidos, os juízes que passam a atuar nos Juizados Especiais Criminais enfrentam dificuldades para assumir este novo papel. Entre os entrevistados, foi freqüente o reconhecimento de que se trata de uma mudança significativa:

Eu diria que a mudança é fundamental, porque enquanto a figura do julgador na justiça tradicional adota uma postura bastante rígida, com relação ao fato de presidir um processo criminal, na justiça consensual, e aqui nos juizados especiais criminais, a figura do juiz se transmuda, o juiz passa a ser uma espécie de conciliador, uma espécie de aconselhador até mesmo das partes. Muitas vezes se pacificam os ânimos das pessoas, e aí um dos desejos do legislador, ao editar a lei 9.099, que é justamente o de restabelecer a harmonia nas relações.

O reconhecimento de que se trata de uma nova função, voltada para a recomposição dos laços de sociabilidade, que passa a ser exigida dos juízes, em vez de uma simples decisão punitiva ou absolutória de uma figura neutra e alheia ao ambiente social, começa a aparecer no discurso de alguns magistrados:

Eu acho que o juiz passa a ter uma função muito mais ativa. Antigamente a função do juiz era praticamente ouvir as partes, ouvir, antes o juiz era um grande ouvido, digamos assim. E ao final, depois de tanto ouvir, prolatava uma sentença. Agora, eu acho muito interessante essa disposição do art. 72, que diz que competirá ao magistrado explicar os objetivos da audiência, e eu acho que essa explicação, se feita de um maneira bem adequada ao caso concreto, produz resultados, em níveis pedagógicos, fantásticos. Então eu acho que o juiz passa a ser um agente de pacificação social, dependendo da postura dele nessa audiência inicial.

Com uma visão mais reticente a respeito da nova sistemática processual, um dos entrevistados manifestou opinião diversa, no sentido de que o papel que agora se exige do juiz já deveria ser praticado na sistemática anterior:

O julgador virou mais um conciliador, ele tem agora a lei a favor dele, embora eu me lembre que na prática muitas vezes eu tentava, antes da Lei 9.099, fazer certas conciliações, dentro do possível. Por exemplo, essas lesões corporais causadas por marido na mulher, eu acho até que era mais eficiente o sistema, porque a gente julgava e dava o sursis, com uma condição para o marido cumprir. Normalmente essas lesões eram decorrentes de alcoolismo do marido, então se colocava no sursis a obrigatoriedade dele se submeter a tratamento, acompanhamento dos alcoólicos anô- 
nimos. Então a impressão que se tinha é que não gerava tanta impunidade. E a impressão que eu tenho é que em relação às mulheres vítimas de violência doméstica essa lei acaba gerando uma certa impunidade, porque a mulher não chega nem a representar. Se ao menos houvesse uma medida, pagasse uma multa, prestasse serviços à comunidade, mas o marido simplesmente olha para a mulher na hora, o juiz pergunta: a senhora quer representar contra o seu marido, e pelo olhar dele ela acaba não tendo coragem de representar, enquanto que antes, quando não era condicionada a representação e o promotor é que oferecia a denúncia, podia a vítima mentir, mas ela era advertida que não deveria mentir. Na verdade, se aplicava uma pena mínima, curta, se dava o sursis, e depois, quando entrou em vigor a nova parte geral de 84 , se podia aplicar prestação de serviços a comunidade, multa, quer dizer, penas alternativas. Eu acho que nesse tocante a lei não foi muito feliz, agora as pesquisas, as estatísticas é que vão mostrar.

Quanto à existência de iniciativas institucionais para a conscientização e o preparo dos operadores jurídicos sobre as funções que lhes foram delegadas nos Juizados Especiais Criminais, constatou-se que muito pouco tem sido feito. A maioria dos atuais juízes teve formação acadêmica que não contemplou a possibilidade de informalização processual. Nessa fase de implantação da Lei 9.099/95, a busca de resultados positivos tem dependido do empenho daqueles juízes que assumiram a nova legislação como um avanço, seja na perspectiva da conciliação, do desafogamento do judiciário, seja de fim da impunidade para os pequenos delitos:

Eu não sei se está havendo uma preocupação, por exemplo, dentro da Escola da Magistratura, quando dos cursos de preparação para o concurso, em enfatizar essa questão. Também não sei se dentro da Corregedoria está havendo essa preocupação. Acho que hoje em dia a coisa se resolve mais dependendo da forma como o juiz encara a lei 9.099, e como o próprio juiz encara o seu papel e como o juiz pode se adaptar a esse novo papel. Ele pode se adaptar ou não. Então eu posso estar errada, mas imagino que ainda não estamos na fase da formação dos juízes, de largada. Acho que os magistrados que já estavam na judicância antes do advento da lei estão se adaptando, e acredito que esses magistrados é que vão passar essa experiência para os novos magistrados.

Uma das entrevistadas lamentou essa falta de preocupação institucional mais efetiva para a formação dos juízes que vão atuar nos Juizados Especiais Criminais, pela compreensão de que depende em grande medida da conduta dos juízes a configuração dessas novas instâncias judiciais informalizadas:

Uma outra sugestão é que se se promovesse mais uma reflexão sobre o papel dos operadores jurídicos no JEC, porque se os operadores que estiverem naquela audiência não tiverem um posicionamento, uma visão do JEC como algo de uma eficácia social muito grande, nós vamos perder a chance de poder fazer um bom trabalho em termos de pacificação e de luta contra a impunidade. Então eu acho que essa reflexão seria importante, não sei se através de cursos específicos, do estímulo dos magistrados a fazerem publicações, sobre esse assunto especificamente: qual a importância do operador jurídico no JEC enquanto atuação na comunidade.

\section{Conclusão: as antinomias da informaliza- ção da justiça penal}

Boaventura de Sousa Santos, no início dos anos 80, em um trabalho exploratório que visava a construção de novas hipóteses de trabalho e o alargamento do campo analítico da sociologia jurídica para o estudo do fenômeno informalista, reconhecia a carência de uma sólida base empírica que desse sustentação às suas proposições, mas sugeria que a novidade nos programas de informalização e comunitarização da justiça era que, se até aquele momento as classes oprimidas foram desorganizadas individualmente - enquanto cidadão, eleitor ou beneficiário da previdência -, no futuro passaria a sê-lo em nível societal ou comunitário - como moradores de um bairro, trabalhadores de uma fábrica, consumidores de um produto. A hipótese formulada à época era de que a organização comunitária tutelada pelo Estado se- 
ria uma forma de desorganização das classes trabalhadoras no capitalismo tardio (Sousa Santos, 1985, pp. 92-93).

Na medida em que o Estado consegue, pela via da informalização, articular ao mesmo tempo uma resposta à crise fiscal e o controle sobre ações e reações sociais dificilmente reguláveis por processos jurídicos formais, ele está de fato a expandir-se por sobre a sociedade civil. A dicotomia Estado/sociedade civil, tão cara ao pensamento da modernidade, deixa de ter sentido teórico, e o controle social pode ser executado na forma de participação social, a violência na forma de consenso, a dominação de classe, na forma de ação comunitária.

Assim, como o próprio projeto da modernidade encontra-se permanentemente tensionado entre o aumento da regulação e a demanda por emancipação, Sousa Santos já visualizava, na época, a presença de um elemento emancipador nas reformas informalizantes: sua associação ideológica a símbolos emancipatórios com forte implantação no imaginário social (participação, auto-gestão etc.). Nesse sentido, embora aprisionados por uma estratégia global de controle social, estes símbolos apresentariam um potencial utópico ou transcendente, que faria com que a justiça informal não pudesse "manipular" sem oferecer algum pedaço genuíno de conteúdo ao público que vai ser manipulado (Sousa Santos, 1985, pp. 97-98).

No caso dos Juizados Especiais Criminais brasileiros, embora a Lei 9.099/95 tenha previsto a utilização de conciliadores escolhidos fora dos quadros da justiça criminal, até hoje essa disposição legal não foi implementada, e os juízes que atuam nos Juizados são os mesmos que atuam nas Varas Criminais, valendo-se mais de uma relação de poder hierárquica e intimidatória sobre as partes para encaminhar uma solução do caso do que de uma proximidade advinda de vínculos societais comunitários.

Em vez de permitir um acesso mais fácil a grupos excluídos do sistema judicial, compensando suas limitações, Lance e Bohn concluem que, no caso norte-americano, os centros de justiça informal funcionam mais como saída do que como entrada no sistema de justiça formal, sendo mais bem-sucedidos em remover do sistema casos considerados inúteis ou menores, que em sua grande maioria envolvem mulheres, negros e pessoas de nível socioeconômico baixo, do que em fornecer uma forma mais acessível de justiça.

Nesse ponto, constatou-se que, no caso dos Juizados Especiais Criminais brasileiros, há uma situação bastante diferenciada. Em vez de retirar do sistema formal os casos considerados de menor potencial ofensivo, a Lei 9.099/95 incluiu esses casos no sistema, através de mecanismos informalizantes para o seu ingresso e processamento. A dispensa da realização do inquérito policial para os delitos de competência dos Juizados Especiais Criminais retirou da autoridade policial a prerrogativa que tinha de selecionar os casos considerados mais "relevantes", que resultava no arquivamento da grande maioria dos pequenos delitos. O problema é que a estrutura judiciária não foi adequada para o recebimento dessa nova demanda, que passou a representar quase $90 \%$ do movimento processual penal.

A especificidade do caso brasileiro é que a informalização da justiça penal na verdade não ampliou o controle social formal do Estado sobre novas condutas, uma vez que esse controle era exercido pelas delegacias de polícia. Na prática, as delegacias acabavam cumprindo informalmente uma função de filtro para a descriminalização de certas condutas, como as ameaças e lesões leves no ambiente doméstico, consideradas de menor importância para ingressar no sistema judicial. A Lei $9.099 / 95$ permitiu a incorporação desses delitos ao sistema judicial, numa espécie de recriminalização, substituindo o delegado pelo juiz no exercício da função de mediação. Enquanto a mediação policial, informal e arbitrária era freqüentemente combinada com mecanismos de intimidação da vítima (sobrevitimização) e do acusado, a mediação judicial tende a ampliar o espaço para a explicitação do conflito e a adoção de uma solução de consenso entre as partes, reduzindo a impunidade.

É preciso reconhecer, portanto, os aspectos emancipatórios que fazem parte do processo de informalização da justiça no caso brasileiro. No entanto, são justamente essas características as 
mais facilmente relegadas quando da implementação prática das medidas informalizantes. A manutenção do sentido emancipatório do informalismo depende de níveis de entusiasmo moral, consenso e convencimento por parte dos operadores jurídicos, especialmente os juízes/conciliadores, a fim de evitar que procurem reforçar seu status e autoridade adotando toda a pompa formalista: trajes e discursos, procedimentos etc.

Além disso, é preciso destacar que tendências históricas e atuais apontam para a mesma conclusão: formalidades criam barreiras, mas também proporcionam um espaço no qual é possível proteger os setores socialmente desfavorecidos, enquanto que procedimentos informais são mais facilmente manipuláveis. Isto sugere que a efetivação de direitos através de procedimentos informais somente pode ser bem-sucedida se forem ultrapassadas as limitações inerentes à falta de apoio jurídico àqueles que pretendem exercer estes direitos. Portanto, um extraordinário esforço será necessário para conduzir o movimento de informalização procedimental da justiça em uma direção favorável. Os resultados deste esforço vão ter um significativo impacto sobre a vida cotidiana das pessoas comuns.

No Brasil, o processo de abertura e informalização da prestação estatal de justiça ocorre em uma situação na qual ainda não há de fato um Estado de Direito funcionando plenamente sob critérios racionais-legais de legitimação. O Estado brasileiro ainda não rompeu com relações tradicionais de poder, que pouco espaço concedem para a representação dos interesses e reivindicações populares no quadro institucional. Particularmente, o poder judiciário, pelo distanciamento que the confere um discurso especializado e somente acessível aos estudiosos do direito, permanece hermético ao senso comum e seletivo em suas decisões, além de disputar espaço com métodos informais de resolução de conflitos, que vão desde formas comunitárias de mediação até a atuação do próprio sistema policial, que em muitas situações cria a sua própria legalidade.

A seletividade do sistema judicial opera em duas vias: enquanto no âmbito civil a promoção de demandas depende da capacidade da parte em identificar seus direitos lesados e arcar com as custas do processo, no âmbito penal somente chegam ao judiciário os inquéritos policiais dos crimes dolosos contra a vida e contra a propriedade, ficando sob o arbítrio policial os delitos relacionados com a conflitualidade interpessoal nas favelas e cortiços, das relações domésticas e de vizinhança, das relações entre vendedor e consumidor, de patrão e empregado. Em todos esses contextos, a violência interpessoal emerge como um mecanismo de excesso de poder, ${ }^{7}$ em que a parte mais forte impõe a sua vontade através da humilhação do outro, em relacionamentos sociais freqüentemente duradouros.

Para tirar as lições da implantação da Lei 9.099/95 no âmbito criminal, na comparação com as demais experiências de informalização da justiça penal, é preciso compreender essa especificidade do Estado brasileiro, em que se delegou à polícia o relacionamento com a maioria da população para a intermediação dos seus conflitos, e as salas de audiência nas Varas Criminais foram reservadas à punição pública de ladrões e homicidas. ${ }^{8}$

Os Juizados Especiais Criminais, tendo surgido sob a ideologia da conciliação e da dispersão para desafogar o judiciário, acabaram abrindo as portas da justiça penal a uma conflitualidade antes abafada nas delegacias, e para a qual o Estado é chamado a exercer um papel de mediador, mais do que punitivo. Com a promessa de resolver disputas por meio da comunicação e do entendimento, e permitindo uma intervenção menos coercitiva e mais dialógica, em um espaço estrutural (a domesticidade, os relacionamentos interpessoais) que antes ficava à margem da prestação estatal de justiça, a informalização da justiça penal pode ser um caminho para o restabelecimento do diálogo, contribuindo para reverter a tendência de dissolução dos laços de sociabilidade no mundo contemporâneo.

\section{NOTAS}

1 Sobre as formas de legitimidade em Max Weber, ver Economia y sociedade, pp. 170 ss., em que Weber, ao estabelecer uma tipologia da dominação, começa de- 
finindo as formas de legitimidade, vista esta última como fundamento de toda dominação duradoura.

2 Sobre este tema, ver o vol. 2 da obra O processo civilizador, de Norbert Elias, sobre a formação do Estado, em especial o capítulo II, "Sobre a sociogênese do Estado", pp. 87-190.

3 Sobre a dicotomia Estado/sociedade civil, ver a obra de Bobbio e Bovero (1986), em que é traçado um paralelo entre o modelo hegeliano e o modelo marxista de distinção entre sociedade civil e Estado, e também, no âmbito da sociologia, o artigo de Boaventura de Souza Santos (1986), "Para uma sociologia da distinção Estado/sociedade civil", publicado em obra coletiva organizada por Doreodó Araújo Lyra em homenagem a Roberto Lyra Filho, intitulada Desordem e processo.

4 Sobre "tolerância zero", ver Loïc Wacquant (2001).

5 Para se ter uma amostra das pesquisas empíricas sobre a informalização da justiça norte-americana, ver os artigos de Lance Selva e Robert Bohm (1987); Stella Hughes e Anne Schnider (1989); Dennis Palumbo e Michael Musheno (1994); ver também a tese de Luis Roberto Cardoso de Oliveira (1989), em que analisa as sessões de mediação de pequenas causas cíveis de um ponto de vista antropológico.

6 Para se ter uma idéia, no Estado de São Paulo, os primeiro Juizados Especiais Criminais somente foram criados no ano de 1998.

7 Sobre a noção de violência como um mecanismo de excesso de poder, ver o artigo de José Vicente Tavares dos Santos (1995, pp. 290-291): "Em seu conjunto, poderíamos considerar a violência como um dispositivo de poder, no qual se exerce uma relação específica com o outro, mediante o uso da força e da coerção: isto significa estarmos diante de uma modalidade de prática disciplinar, um dispositivo, que produz um dano social, ou seja, uma relação que atinge o outro com algum tipo de dano. [...] a violência compõe-se por linhas de força, consiste em um ato de excesso presente nas relações de poder. Os processos de violência efetivam-se em um espaço-tempo múltiplo, recluso ou aberto, instaurando-se com justificativas racionais, desde a prescrição de estigmas até a exclusão, simbólica ou física. Porém, no dispositivo da violência, aparecem também linhas de fratura, o que possibilitaria a passagem a outros dispositivos, a outras formas de possibilidade; a emergência de lutas sociais contra a violência poderia representar uma dessas linhas de fratura no dispositivo da violência."

8 Sobre este tema, ver o artigo de Roberto Kant de Lima (1996, pp. 165-177).

\section{BIBLIOGRAFIA}

BERGALLI, Roberto (1991), "Sociology of penal control within the framework of the sociology of law". Oñati Proceedings, I. I. S. L., 10: 25-45.

BOBBIO, Norberto e BOVERO, Michelangelo (1986), Sociedade e Estado na filosofia politica moderna. São Paulo, Brasiliense (trad. Carlos Nelson Coutinho).

CERVINI, Raúl (1995), Os processos de descriminalização. São Paulo, Ed. Revista dos Tribunais.

COSTA-LASCOUX, Jacqueline (1994), "La régulation des petits désordres sociaux". Les Cabiers de La Sécurité Intérieure, 18: 139$158,4^{\circ}$ trimestre.

DIAS, J. F. e ANDRADE, M. C. (1992), Criminologia - o bomem delinqüente e a sociedade criminógena. Coimbra, Ed. Coimbra, 1. reimpressão.

HUGHES, Stella e SCHNEIDER, Anne (1989), "Victm-offender mediation: a survey of program characteristics and perceptions of effectiveness". Crime e delinquency, 35(a2).

KANT DE LIMA, Roberto (1996), “A administração dos conflitos no Brasil: a lógica da punição", in VELHO, G. e ALVITO, M., Cidadania e violência, Rio de Janeiro, Ed. $\mathrm{UFRJ} / \mathrm{FGV}$.

LIMA LOPES, José Reinaldo de (1996), "Uma introdução à história social e política do processo", in WOLKMER, A. C. (org.), Fundamentos de história do direito, Belo Horizonte, Ed. Del Rey.

MERRY, Sally Engle (1982), "The social organization of mediation in nonindustrial societies, in ABEL (org.), The politics of informal justice, Nova York, Academic Press, vol. 2.

OLIVEIRA, Luis Roberto Cardoso de (1989), Fairness and communication in small claims courts. Cambridge, Harvard University, mimeo. 
PALUMBO, Denis e MUSHENO, Michael (1994), The political construction of alternative dispute resolution and alternatives to incarceration. Arizona State University, mimeo.

POGGI, Gianfranco (1981), A evolução do Estado moderno: uma introdução sociológica. Rio de Janeiro, Zahar Editores (trad. Álvaro Cabral).

SELVA, Lance e BOHM, Robert (1987), "A critical examination of the informalism experiment in the administration of justice". Crime and Social Justice, 29: 43-57.

SOUSA SANTOS, Boaventura (1985), "O direito e a comunidade: as transformações recentes na natureza do poder do Estado no capitalismo avançado". Ciências Sociais Hoje, 3, Anpocs.

. (1986), "Para uma sociologia da distinção Estado/sociedade civil", in LYRA, Doreodó Araújo, Desordem e processo, Porto Alegre, Ed. Jorge Fabris.

TAVARES DOS SANTOS, José Vicente (1995), "A violência como dispositivo de excesso de poder". Sociedade e Estado, 2 (vol. x).

WACQUANT, Lö̈c (2001), As prisões da miséria. Rio de Janeiro, Jorge Zahar Editor.

WEBER, Max (1996), Economía y sociedad: esbozo de sociología comprensiva. 2. ed. México, Fondo de Cultura Económica, décima reimpressão (trad. José Medina Echavarría et. al.).

ZAFFARONI, Eugenio Raúl (1991), Em busca das penas perdidas: a perda de legitimidade do sistema penal. Rio de Janeiro, Editora Renavan (trad. Vania Romano Pedrosa e Amir Lopes da Conceição). 
JUIZADOS ESPECIAIS CRIMINAIS: UMA ABORDAGEM SOCIOLÓGICA SOBRE A INFORMALIZAÇÃO DA JUSTIÇA PENAL NO BRASIL

Rodrigo Ghiringhelli de Azevedo

\section{Palavras-Chave}

Controle penal; Administração da justiça penal; Informalização; Juizados Especiais Criminais; Conflito social e mediação.

Por meio do estudo de caso da implantação dos Juizados Especiais Criminais na cidade de Porto Alegre, confrontando as previsões legais com a realidade empírica de um novo modelo de justiça penal, buscou-se compreender no presente trabalho o sentido e os limites da informalização da prestação estatal de justiça penal no Brasil, desde a promulgação da Lei 9.099/95. Ao retirar do domínio da polícia o exercício da seletividade e ao oferecer à vítima a possibilidade de participação no processo, o sistema penal informalizado abre novas perspectivas, substituindo a punição pela mediação e a violência pelo diálogo. Porém esbarra na dinâmica burocratizante e autoritária dos mecanismos de vigilância e controle social institucionalizados.
SPECIAL CRIMINAL COURTS: A SOCIOLOGICAL APPROACH ON THE INFORMALIZATION OF THE PENAL JUSTICE IN BRAZIL

Rodrigo Ghiringhelli de Azevedo

\section{Keywords}

Penal Control, Administration of Penal Justice, Informalization, Special Criminal Courts, Social Conflict and Mediation.

Through a case study of the implantation of the Juizados Especiais Criminais (Special Criminal Courts) in the city of Porto Alegre, confronting legal previews with empirical reality of a new model of criminal justice, this article aims to understand the meaning and the limits of the informalization of the criminal justice in Brazil, since the enactment of the 9.099/95 law. By taking away from the police the exercise of selectivity, and giving to the victim the possibility of participating in the process, the informalized criminal system opens up new possibilities, changing punishment by mediation and violence by dialog, even though it collides with the bureaucratic and authoritarian dynamics of the institutionalized vigilance and social control mechanisms.
TRIBUNAUX PÉNAUX SPÉCIAUX: UN ABORDAGE SOCIOLOGIQUE À PROPOS DU CARACTĖRE INFORMEL DE LA JUSTICE PÉNALE AU BRÉSIL

Rodrigo Ghiringhelli de Azevedo

\section{Mots-clés}

Contrôle pénal; Administration de la justice pénale; Caractère informel; Tribunaux Pénaux Spéciaux; Conflit social et médiation.

L'auteur a cherché, par l'étude de l'implantation des Tribunaux Pénaux Spéciaux dans la ville de Porto Alegre, à comprendre le sens et les limites du caractère informel de la prestation étatique de la justice pénale au Brésil, depuis la promulgation de la Loi 9.099/95. Dans ce travail, il confronte les prévisions légales avec la réalité empirique d'un nouveau modèle de justice pénale. En soustrayant à la police l'exercice de la sélectivité et en offrant à la victime la possibilité de participation au procès, le système pénal informatisé ouvre de nouvelles perspectives, substituant la punition par la médiation et la violence par le dialogue. Néanmoins, il se heurte à la dynamique bureaucratisante et autoritaire des mécanismes de vigilance et de contrôle social institutionnalisés. 